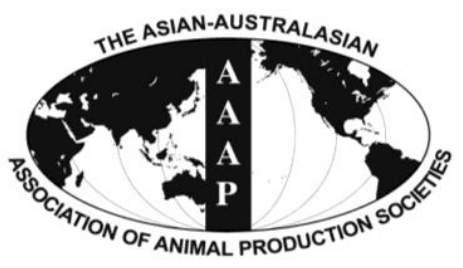

Open Access

Asian Australas. J. Anim. Sci.

Vol. 28, No. 8 : 1202-1208 August 2015

http://dx.doi.org/10.5713/ajas.14.0901

www.ajas.info

pISSN 1011-2367 elSSN 1976-5517

\title{
Effects of L-tryptophan, Fructan, and Casein on Reducing Ammonia, Hydrogen Sulfide, and Skatole in Fermented Swine Manure
}

\author{
Q. K. Sheng ${ }^{1,2, *}$, Z. J. Yang ${ }^{3}$, H. B. Zhao ${ }^{1}$, X. L. Wang ${ }^{1}$, and J. F. Guo ${ }^{1}$ \\ ${ }^{1}$ Institute of Animal Science and Veterinary Medicine, Shandong Provincial Academy of Agricultural Sciences, \\ Jinan 250100, China
}

\begin{abstract}
The effects of daily dietary Bacillus subtilis (Bs), and adding L-tryptophan, fructan, or casein to fecal fermentation broths were investigated as means to reduce the production of noxious gas during manure fermentation caused by ammonia, hydrogen sulfide $\left(\mathrm{H}_{2} \mathrm{~S}\right)$, and 3-methylindole (skatole). Eighty swine $(50.0 \pm 0.5 \mathrm{~kg})$ were equally apportioned to an experimental group given Bs in daily feed, or a control group without Bs. After 6 weeks, fresh manure was collected from both groups for fermentation studies using a $3 \times 3$ orthogonal array, in which tryptophan, casein, and fructan were added at various concentrations. After fermentation, the ammonia, $\mathrm{H}_{2} \mathrm{~S}$, L-tryptophan, skatole, and microflora were measured. In both groups, L-tryptophan was the principle additive increasing skatole production, with significant correlation $(r=0.9992)$. L-tryptophan had no effect on the production of ammonia, $\mathrm{H}_{2} \mathrm{~S}$, or skatole in animals fed Bs. In both groups, fructan was the principle additive that reduced $\mathrm{H}_{2} \mathrm{~S}$ production $(r=0.9981)$. Fructan and Bs significantly interacted in $\mathrm{H}_{2} \mathrm{~S}$ production $(\mathrm{p}=0.014)$. Casein was the principle additive affecting the concentration of ammonia, only in the control group. Casein and Bs significantly interacted in ammonia production $(\mathrm{p}=0.039)$. The predominant bacteria were Bacillus spp. CWBI B1434 (26\%) in the control group, and Streptococcus alactolyticus AF201899 (36\%) in the experimental group. In summary, daily dietary Bs reduced ammonia production during fecal fermentation. Lessening L-tryptophan and increasing fructan in the fermentation broth reduced skatole and $\mathrm{H}_{2} \mathrm{~S}$. (Key Words: Swine Manure, L-tryptophan, Fructan, Casein, Ammonia, $\mathrm{H}_{2} \mathrm{~S}, \mathrm{Skatole}$, B. subtilis)
\end{abstract}

\section{INTRODUCTION}

Environmental contamination caused by swine manure has provoked much public concern. More than 160 noxious substances have been discovered in swine waste (Le et al., 2005). Ammonia and hydrogen sulfide $\left(\mathrm{H}_{2} \mathrm{~S}\right)$ are routinely measured, and 3-methylindole (skatole), a byproduct of tryptophan degradation, also increases fecal odor. Deposition of skatole in adipose tissues can taint the meat, with harmful consequences for the beef and pork industries.

In efforts to reduce the production of ammonia, $\mathrm{H}_{2} \mathrm{~S}$, and skatole, dietary additives have been investigated. These

\footnotetext{
* Corresponding Author: Q. K. Sheng. Tel: +86-531-88622516, Fax: +86-531-88622516, E-mail: shengqingkai71@163.com

${ }^{2}$ Shandong Provincial Key Laboratory of Animal Disease Control and Breeding, Jinan 250100, China.

3 Shandong Meishida Agriculture and Husbandry Technology, Jinan 251400, China.

Submitted Dec. 1, 2014; Revised Jan. 6, 2015; Accepted Feb. 4, 2015
}

have included probiotics (Wutzke et al., 2010), fructan (Xu et al., 2002), and enzymes or amino acids (Vhile et al., 2012). Castration and vaccination have also been used to control the production of noxious gases. Among the probiotics, effective microorganisms, Bacillus subtilis (Bs), and lactic acid bacteria reduce the production of ammonia by modifying the intestinal microflora (Jeon et al., 1996). Dietary fructan has been shown to selectively promote Bifidobacterium spp. in the gut, thereby reducing the production of skatole $(\mathrm{Li}, 2009)$, and there is evidence for the prebiotic effects of inulin-derived fructans in humans (Salazar et al., 2014). Amino acid-balanced diets (such as those containing tryptophan) were shown to reduce the protein ratio in daily feedings, which led to less ammonia production in swine manure (Powers et al., 2007). The purpose of the above methods was to reduce the production of foul-smelling gas from within the bodies of live swine. To our knowledge, there have been no investigations to reduce the unpleasant odor of fecal matter once outside the 
body, i.e., conducted in vitro.

The present study evaluated the effects of externally applied tryptophan, fructan, or casein on manure fermentation, and noted the interactions among these additives and dietary Bs. Our results should provide a solid reference for studies aimed at reducing the odor of fecal waste outside the live swine body.

\section{MATERIALS AND METHODS}

The Animal Welfare Committee of Shandong Academy of Agricultural Sciences reviewed and approved the study protocol.

\section{Materials}

Eighty Duchangda Sanyuan commercial hybrid pigs $(50 \pm 0.5 \mathrm{~kg}$ ) were purchased from Shangdong Lvan (Jinan, China). Bs $\left(10^{9} \mathrm{CFU} / \mathrm{g}\right)$ was purchased from Shandong Huamu Tianyuan Nongmu (Jinan, China).

\section{Experimental design}

The 80 pigs were randomly divided into an experimental group and a control group $(n=40$, each), constituting four replicates in each group and ten pigs in each replicate. Both groups were raised on a concrete floor. Pigs in the experimental group $\left(\mathrm{Bs}^{+}\right)$were given a cornsoybean basal diet supplemented with $0.2 \% \mathrm{Bs}$. The control group $\left(\mathrm{Bs}^{-}\right)$received the same diet, but without the bacteria. The basal diet was prepared in accordance with the China feeding standard for swine (NY/T65-2004).

After 6 weeks, fresh manure was quickly collected, before feeding in the morning, from 2 randomly selected pigs in each replicate for subsequent studies (Yokoyama and Carlsonet, 1974). In brief, $280 \mathrm{~g}$ of each fecal sample was first suspended in $2.8 \mathrm{~L}$ anaerobic mineral buffer $(5.0$ $\mathrm{g} / \mathrm{L} \mathrm{NaHCO} 3,0.9 \mathrm{~g} / \mathrm{L} \mathrm{NaCl}, 0.9 \mathrm{~g} / \mathrm{L}\left(\mathrm{NH}_{4}\right)_{2} \mathrm{SO}_{4}, 0.45 \mathrm{~g} / \mathrm{L}$ $\mathrm{KH}_{2} \mathrm{PO}_{4}, 0.45 \mathrm{~g} / \mathrm{L} \mathrm{K}_{2} \mathrm{HPO}_{4} \cdot 3 \mathrm{H}_{2} \mathrm{O}, 0.03 \mathrm{~g} / \mathrm{L} \mathrm{CaC1} 1_{2} \cdot 2 \mathrm{H}_{2} \mathrm{O}$,

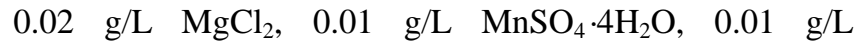
$\mathrm{CoCl}_{2} \cdot 6 \mathrm{H}_{2} \mathrm{O}, 0.01 \mathrm{~g} / \mathrm{L} \mathrm{FeSO}_{4} \cdot 7 \mathrm{H}_{2} \mathrm{O}, 0.1 \mathrm{~g} / \mathrm{L}$ cysteine). The suspensions were subsequently transferred to sterile plastic bags filled with $\mathrm{CO}_{2}$, thoroughly shaken for $5 \mathrm{~min}$, and filtered through 6 layers of gauze to remove small particles. The filtrate from each suspension was distributed into 27 aliquots with $100 \mathrm{~mL}$ in each flask, and divided into 9 groups based on the amounts of L-tryptophan, fructan, or casein added to each flask (Table 1). The broths were incubated anaerobically for $24 \mathrm{~h}$ at $38^{\circ} \mathrm{C}$. A $20-\mathrm{mL}$ sample was taken from each flask to measure the gas composition. One milliliter of clear fermented broth was separately taken from both the $\mathrm{Bs}^{+}$and $\mathrm{Bs}^{-}$samples (the blank, containing no added L-tryptophan, fructan, or casein, broth 1 in Table 1), mixed, and stored at $-20^{\circ} \mathrm{C}$ for microflora isolation and
Table 1. The doses of L-tryptophan, fructan and casein in pig manure fermentation broths

\begin{tabular}{lccc}
\hline Group number & L-tryptophan & Casein $(\%)$ & Fructan $(\%)$ \\
\hline 1 & 0 & 0 & 0 \\
2 & 0 & 0.125 & 0.75 \\
3 & 0 & 0.25 & 1.5 \\
4 & 0.05 & 0 & 0.75 \\
5 & 0.05 & 0.125 & 1.5 \\
6 & 0.05 & 0.25 & 0 \\
7 & 0.1 & 0 & 1.5 \\
8 & 0.1 & 0.125 & 0 \\
9 & 0.1 & 0.25 & 0.75 \\
\hline
\end{tabular}

identification.

\section{Measurement of substances in the noxious gas}

The fermented broth samples were measured after filtration through a $0.45-\mu \mathrm{m}$ organic membrane. Ammonia was measured by the Nessler reagent colorimetric method. $\mathrm{H}_{2} \mathrm{~S}$ was quantified via sulfate-iodometric titration. Ltryptophan and skatole were measured using highperformance liquid chromatography, with reference to $\mathrm{Li}$ (2009), and conducted at the Center for Food Quality Supervision and Testing Ministry of Agriculture (Jinan, China).

\section{Isolation and identification of fecal bacteria in the fermentation broth}

Genomic DNA of fecal bacteria was purified using an OMEGA Stool DNA kit (Omega Bio-Tec, Norcross, GA, USA). Using V3-340F (5'-FAM-TCCTACGGGAGGCA GCAGT-3') and V3-532R (5'-TCCTACGGGAGGCAGC AGT-3') as universal primers, the $\mathrm{V} 3$ region of $16 \mathrm{~S}$ rDNA was amplified through fluorescence-based polymerase chain reaction-single-strand conformation polymorphismfragment length polymorphism (F-PCR-SSCP-FLP) methods, as described by Zhang et al. (2000). The 195-bp PCR products were analyzed with an Applied Biosystems 3730xl DNA Analyzer (Applied Biosystems, Carlsbad, CA, USA, 96-capillary array), in which the amount of each specific bacteria was quantified by the area size of their corresponding peaks. The $16 \mathrm{~S}$ rDNA clone library (target fragment size $1.6 \mathrm{~kb}$ ) was constructed by amplifying the $16 \mathrm{~S}$ rDNA region of each bacteria using the $\mathrm{V} 3$ region fluorescent-labeled primers. The PCR products were purified and sequenced at the Biotechnology Research Center, Shandong Academy of Agricultural Sciences. All the sequences were BLASTed in the NCBI database to identify the bacterial species, and quantified using Mega6 software (http://www.megasoftware.net).

\section{Statistical analyses}

The amounts of ammonia, $\mathrm{H}_{2} \mathrm{~S}$, and skatole of the $\mathrm{Bs}^{+}$ 
Table 2. Quantification of ammonia, $\mathrm{H}_{2} \mathrm{~S}$ and skatole after the manure fermentation

\begin{tabular}{|c|c|c|c|c|c|c|c|c|c|c|}
\hline Group & & 1 & 2 & 3 & 4 & 5 & 6 & 7 & 8 & 9 \\
\hline \multirow{2}{*}{$\begin{array}{c}\mathrm{NH}_{3} \\
(\mathrm{~g} / \mathrm{L})\end{array}$} & $S_{-1}$ & $1.15 \pm 0.09$ & $1.05 \pm 0.10$ & $1.30 \pm 0.11$ & $1.17 \pm 0.09$ & $1.01 \pm 0.08$ & $1.68 \pm 0.11$ & $1.10 \pm 0.09$ & $0.86 \pm 0.09$ & $1.27 \pm 0.11$ \\
\hline & Bs $(+)$ & $0.80 \pm 0.05^{\mathrm{A}}$ & $0.47 \pm 0.04^{\mathrm{A}}$ & $0.62 \pm 0.03^{\mathrm{A}}$ & $1.06 \pm 0.06^{\mathrm{a}}$ & $0.70 \pm 0.05^{\mathrm{A}}$ & $0.62 \pm 0.04^{\mathrm{A}}$ & $0.97 \pm 0.04^{\mathrm{a}}$ & $0.78 \pm 0.03^{\mathrm{a}}$ & $0.84 \pm 0.03^{\mathrm{A}}$ \\
\hline \multirow{2}{*}{$\begin{array}{l}\mathrm{H}_{2} \mathrm{~S} \\
(\mathrm{mg} / \mathrm{L})\end{array}$} & Bs (-) & $0.46 \pm 0.03$ & $0.33 \pm 0.02$ & $0.38 \pm 0.03$ & $0.36 \pm 0.02$ & $0.35 \pm 0.02$ & $0.42 \pm 0.03$ & $0.41 \pm 0.03$ & $0.37 \pm 0.03$ & $0.36 \pm 0.03$ \\
\hline & Bs $(+$ & $0.41 \pm 0.03^{\mathrm{a}}$ & $0.24 \pm 0.02^{\mathrm{A}}$ & $0.35 \pm 0.02^{\mathrm{a}}$ & $0.30 \pm 0.03^{\mathrm{a}}$ & $0.29 \pm 0.02^{\mathrm{A}}$ & $0.39 \pm 0.02^{\mathrm{a}}$ & $0.36 \pm 0.03^{\mathrm{a}}$ & $0.35 \pm 0.02^{\mathrm{a}}$ & $0.27 \pm 0.02^{\mathrm{A}}$ \\
\hline \multirow{2}{*}{$\begin{array}{l}\text { Trp } \\
(\mathrm{mg} / \mathrm{L})\end{array}$} & Bs (-) & $30.70 \pm 1.12$ & $17.25 \pm 0.96$ & $27.92 \pm 1.16$ & $27.33 \pm 1.12$ & $36.74 \pm 1.33$ & $30.04 \pm 1.19$ & $28.56 \pm 1.05$ & $36.01 \pm 1.10$ & $32.53 \pm 0.97$ \\
\hline & Bs $(+)$ & $18.46 \pm 1.18^{\mathrm{A}}$ & $14.90 \pm 1.14^{\mathrm{a}}$ & $20.49 \pm 0.97^{\mathrm{a}}$ & $13.03 \pm 1.08^{\mathrm{A}}$ & $17.16 \pm 1.15^{\mathrm{A}}$ & $14.62 \pm 1.16^{\mathrm{A}}$ & $19.37 \pm 1.17^{\mathrm{A}}$ & $19.52 \pm 1.06^{\mathrm{A}}$ & $23.99 \pm 1.21^{\mathrm{A}}$ \\
\hline \multirow{2}{*}{$\begin{array}{l}\text { Skatole } \\
(\mathrm{mg} / \mathrm{L})\end{array}$} & Bs (-) & $83.94 \pm 1.25$ & $95.67 \pm 1.42$ & $93.83 \pm 1.03$ & $99.96 \pm 1.07$ & $114.24 \pm 1.25$ & $101.88 \pm 1.36$ & $90.15 \pm 1.21$ & $93.10 \pm 0.94$ & $112.19 \pm 1.36$ \\
\hline & $\mathrm{Bs}(+)$ & $52.91 \pm 1.21^{\mathrm{A}}$ & $71.41 \pm 1.44^{\mathrm{A}}$ & $84.30 \pm 1.31^{\mathrm{a}}$ & $87.50 \pm 1.04^{\mathrm{a}}$ & $89.86 \pm 1.56^{\mathrm{A}}$ & $94.57 \pm 1.33^{\mathrm{a}}$ & $83.96 \pm 1.35^{\mathrm{a}}$ & $82.7 \pm 1.25^{\mathrm{a}}$ & $72.41 \pm 1.05^{\mathrm{A}}$ \\
\hline
\end{tabular}

${ }^{\mathrm{a}}$ Means bearing different superscripts in a column differ significantly $(\mathrm{p}<0.05)$.

${ }^{\mathrm{A}}$ Means bearing different superscripts in a column differ significantly $(\mathrm{p}<0.01) ; \mathrm{n}=8$.

and $\mathrm{Bs}^{-}$groups were compared using one-way analysis of variance and Student's $t$-test. A probability (p) value less than 0.05 was the standard for significance. The generalized linear model procedure (PROC GLM) was used in the $3 \times 3$ orthogonal experimental design, to analyze the average $\mathrm{k}$ values and the residual R values. Duncan's method was used for multi-comparisons $(\mathrm{p}=0.05)$. SAS (V9.1) was used for statistical analyses. Data are presented as means \pm standard error of the mean.

\section{RESULTS}

Effect of different additives on ammonia, $\mathrm{H}_{2} \mathrm{~S}$, and skatole production

The amounts of ammonia, $\mathrm{H}_{2} \mathrm{~S}$, tryptophan, and skatole produced in the fermentation broths prepared from fecal samples from pigs given $\mathrm{Bs}\left(\mathrm{Bs}^{+}\right.$group) were significantly lower than that of pigs of the control group $\left(\mathrm{Bs}^{-}\right)$. This suggests that the addition of Bs in the diet was associated with reduced ammonia, $\mathrm{H}_{2} \mathrm{~S}$, tryptophan, and skatole production in the fermentation broths (Table 2).

\section{Effect of different added substances on the residual $R$ -} value of noxious gas

Casein showed the largest R-value to the ammonia in the fermentation broth in the $\mathrm{Bs}^{+}$group, and L-tryptophan resulted in the largest $\mathrm{R}$ in the $\mathrm{Bs}^{-}$group (Table 3). This indicated that the main experimental additives affecting the $\mathrm{Bs}^{+}$and $\mathrm{Bs}^{-}$groups were different. In the production of $\mathrm{H}_{2} \mathrm{~S}$, fructan resulted in the largest $\mathrm{R}$-value in both groups, which indicated that fructan was the main substance that affected the production of $\mathrm{H}_{2} \mathrm{~S}$. In the result regarding tryptophan, Ltryptophan showed biggest R-value in both groups, indicating that external added tryptophan was the main cause for the tryptophan in the fermentation broth. For skatole, external L-tryptophan showed the biggest R-value, which indicated that external L-tryptophan was the main affecting element.

Regarding the effect of adding casein to the fermentation broth on ammonia production, there was no correlation $(r=-0.1551)$ between $\mathrm{Bs}^{+}$group $(\mathrm{k} 1>\mathrm{k} 2>\mathrm{k} 3)$ and the $\mathrm{Bs}^{-}$group $(\mathrm{k} 1>\mathrm{k} 3>\mathrm{k} 2$; Table 4$)$. This shows that the effects of casein at different concentrations were different in the Bs+ group and the $\mathrm{Bs}^{-}$group. Fructan at different

Table 3. Effect of different additional substances on the residual R-value of noxious gas

\begin{tabular}{|c|c|c|c|c|c|c|}
\hline \multirow{2}{*}{ R-value } & \multicolumn{3}{|c|}{$\mathrm{Bs}(+)$} & \multicolumn{3}{|c|}{ Bs (-) } \\
\hline & L-Trp & Casein & Fructan & L-Trp & Casein & Fructan \\
\hline$\overline{\mathrm{NH}_{3}}$ & $0.30 \pm 0.03^{\mathrm{A}}$ & $0.17 \pm 0.02$ & $0.15 \pm 0.02$ & $0.19 \pm 0.04$ & $0.39 \pm 0.04^{\mathrm{A}}$ & $0.10 \pm 0.02$ \\
\hline $\mathrm{H}_{2} \mathrm{~S}$ & $0.01 \pm 0.03$ & $0.06 \pm 0.01^{\mathrm{A}}$ & $0.08 \pm 0.01^{\mathrm{A}}$ & $0.01 \pm 0.01$ & $0.04 \pm 0.01$ & $0.07 \pm 0.02^{\mathrm{A}}$ \\
\hline $\operatorname{Trp}$ & $6.02 \pm 2.09^{\mathrm{A}}$ & $2.51 \pm 1.01$ & $1.47 \pm 0.77$ & $7.08 \pm 2.32^{\mathrm{A}}$ & $1.30 \pm 0.81$ & $6.54 \pm 1.80^{\mathrm{A}}$ \\
\hline Skatole & $21.10 \pm 2.74^{\mathrm{A}}$ & $8.97 \pm 1.93$ & $8.93 \pm 1.69$ & $14.21 \pm 1.73^{\mathrm{a}}$ & $11.28 \pm 1.44$ & $9.63 \pm 1.87$ \\
\hline
\end{tabular}

${ }^{a}$ Means bearing different superscripts in a row differ significantly $(\mathrm{p}<0.05)$.

${ }^{\mathrm{A}}$ Means bearing different superscripts in a row differ significantly $(\mathrm{p}<0.01) ; \mathrm{n}=8$.

Table 4. Effect of different additional substances on the k-value of noxious gas

\begin{tabular}{|c|c|c|c|c|c|c|}
\hline \multirow{2}{*}{$\mathrm{k}$-value } & \multicolumn{2}{|c|}{ Effect of casein on ammonia } & \multicolumn{2}{|c|}{ Effect of fructan on $\mathrm{H}_{2} \mathrm{~S}$} & \multicolumn{2}{|c|}{ Effect of L-tryptophan on skatole } \\
\hline & $\mathrm{Bs}(-)$ & $\mathrm{Bs}(+)$ & $\mathrm{Bs}(-)$ & $\mathrm{Bs}(+)$ & $\mathrm{Bs}(-)$ & $\mathrm{Bs}(+)$ \\
\hline $\mathrm{k} 1$ & $1.13 \pm 0.14^{\mathrm{a}}$ & $0.87 \pm 0.11^{\mathrm{A}}$ & $0.42 \pm 0.08^{\mathrm{A}}$ & $0.38 \pm 0.07^{\mathrm{A}}$ & $91.15 \pm 1.36$ & $69.54 \pm 1.01$ \\
\hline k2 & $0.97 \pm 0.011$ & $0.71 \pm 0.09$ & $0.35 \pm 0.09$ & $0.30 \pm 0.06$ & $105.36 \pm 1.42^{\mathrm{A}}$ & $90.64 \pm 1.24^{\mathrm{A}}$ \\
\hline $\mathrm{k} 3$ & $1.36 \pm 0.15^{\mathrm{A}}$ & $0.70 \pm 0.08$ & $0.38 \pm 0.08^{\mathrm{a}}$ & $0.33 \pm 0.06^{\mathrm{a}}$ & $98.48 \pm 1.16^{\mathrm{a}}$ & $79.69 \pm 0.99^{\mathrm{a}}$ \\
\hline
\end{tabular}

${ }^{a}$ Means bearing different superscripts in a column differ significantly $(\mathrm{p}<0.05)$.

${ }^{\mathrm{A}}$ Means bearing different superscripts in a column differ significantly $(\mathrm{p}<0.01) ; \mathrm{n}=8$. 
concentrations showed similar effects on $\mathrm{H}_{2} \mathrm{~S}$, since the two effects (both $\mathrm{k} 1>\mathrm{k} 3>\mathrm{k} 2)$ were highly correlated $(r=$ $0.9981)$; $\mathrm{k} 1$ was higher than $\mathrm{k} 3$ in both groups $(\mathrm{p}<0.05)$, which indicated that the $1.5 \%$ added fructan reduced the $\mathrm{H}_{2} \mathrm{~S}$ levels in both the $\mathrm{Bs}^{+}$and $\mathrm{Bs}^{-}$groups. Tryptophan showed similar effects on skatole (both $\mathrm{k} 2>\mathrm{k} 3>\mathrm{k} 1, r=$ $0.9992)$, and $\mathrm{k} 1$ was lower than $\mathrm{k} 3$ in both groups $(\mathrm{p}<0.05)$. This indicated that the $0.1 \%$ added tryptophan increased the concentrations of skatole in both the $\mathrm{Bs}^{+}$and $\mathrm{Bs}^{-}$groups.

\section{Correlation between externally added substances and} Bacillus subtilis

In the $\mathrm{Bs}^{+}$group, there were no associated changes between externally added L-tryptophan and ammonia, $\mathrm{H}_{2} \mathrm{~S}$, tryptophan, or skatole production ( $p>0.05$; Table 5). There was significant correlation between casein and $\mathrm{Bs}$ in the production of ammonia ( $\mathrm{p}=0.0395)$, as well as between fructan and $\mathrm{Bs}$ on the production of $\mathrm{H}_{2} \mathrm{~S}(\mathrm{p}=0.0141)$.

\section{Microflora in then non-supplemented (blank) fermented manure broth}

In the blank broth (i.e., with no added L-tryptophan, fructan, or casein) of the $\mathrm{Bs}^{+}$group, the predominant bacteria were Streptococcus alactolyticus AF201899 (36\%), Lactobacillus amylovorus (16\%), Bacteroidetes bacterium (11\%), and B. asahii strain MA001 (9\%). In the Bs ${ }^{-}$group, the dominate bacteria in the blank broth were Bacillus spp. CWBI B1434 (26\%), Bacteroidetes spp. (18\%), and Lysinibacillus sphaericus strain $13651 \mathrm{~V}(6 \%)$. There were also uncultured bacteria without clear identification that

Table 5. Correlation of different additional substances and Bacillus subtilis

\begin{tabular}{llcccc}
\hline \multicolumn{2}{l}{ Interaction } & $\mathrm{NH}_{3}$ & $\mathrm{H}_{2} \mathrm{~S}$ & Trp & Skatole \\
\hline p-value & L-Trp & 0.3591 & 0.9501 & 0.2559 & 0.7779 \\
& Casein & 0.0395 & 0.9505 & 0.9244 & 0.9479 \\
& Fructan & 0.8594 & 0.0141 & 0.5466 & 0.4016 \\
\hline
\end{tabular}

constituted a high percentage in both groups. The differences in bacterial composition indicated that Bs significantly affected the species of microflora in the fermented manure broth (Table 6).

\section{DISCUSSION}

The ammonia, $\mathrm{H}_{2} \mathrm{~S}$, and skatole produced during pig raising not only adversely affect the growth of pigs, but also contaminate the environment and harm human health. In this study, we found that incorporating Bs in the pigs' daily feed significantly reduced the concentrations of ammonia, $\mathrm{H}_{2} \mathrm{~S}$, and skatole in the manure fermentation broth. Moreover, adding external L-tryptophan increased the production of skatole in the manure fermentation broths. Fructan inhibited the production of $\mathrm{H}_{2} \mathrm{~S}$. The effect of casein to the ammonia production depended on the presence of Bs. These discoveries provide an important reference for the control of noxious gases.

\section{Effects of Bacillus subtilis on the production of ammonia, $\mathrm{H}_{2} \mathrm{~S}$ and skatole in the fermented broth}

Bs is routinely added to the daily swine diet to reduce the production of noxious gas. In the present study, ammonia production from fermentation broths prepared from the fecal matter of pigs given Bs was also reduced compared with that of pigs of the control group, which is consistent with the results of Kim et al. (2005). This may be because Bs secretes proteases that degrade proteins which otherwise transition to ammonia (Zhang et al., 2009). It is also possible that $\mathrm{Bs}$ promotes the presence of Lactobacillus amylovorus in the microflora (Su et al., 2006), which produces amylase (Eom et al., 2009) that facilitate the breakdown of ammonia.

Consistent with the discovery of Lee et al. (2009), in the present study dietary Bs was also associated with less $\mathrm{H}_{2} \mathrm{~S}$ production from the fermentation broths, compared with the

Table 6. The dominant bacteria in blank fermentation broths

\begin{tabular}{llclc}
\hline & \multicolumn{1}{c}{ Num } & Size & \multicolumn{1}{c}{ Strain name } & Proportion (\%) \\
\hline Blank control group & 1. PCR.fsa & 170.52 & Uncultured bacterium & 15 \\
& 2. PCR.fsa & 171.9 & Uncultured bacterium & 13 \\
& 3. PCR.fsa & 172.88 & Lactobacillus sp. DJF_RP24 & 5 \\
& 4. PCR.fsa & 189.61 & Uncultured bacterium & 17 \\
5. PCR.fsa & 192.43 & Lysinibacillus sphaericus strain $13651 \mathrm{~V}$ & 6 \\
Blank test group & 193.37 & Bacillus sp. CWBI B1434 & 26 \\
& 6. PCR.fsa & 194.5 & Uncultured Bacteroidetes bacterium & 18 \\
& 7. PCR.fsa & 168.22 & Uncultured bacterium clone & 12 \\
& 1. PCR.fsa & 169.98 & Bacillus asahii strain MA001 & 9 \\
& 2. PCR.fsa & 187.49 & Uncultured bacterium clone & 16 \\
& 3. PCR.fsa & 191.15 & Lactobacillus amylovorus & 16 \\
& 4. PCR.fsa & 193.34 & AF201899 Streptococcus alactolyticus & 36 \\
& 5. PCR.fsa & 194.3 & Uncultured Bacteroidetes bacterium & 11 \\
\hline
\end{tabular}


control group. This reduction may be caused by metabolites of Bs that contain catalase and oxidase, which decrease the production of $\mathrm{H}_{2} \mathrm{~S}$ (Yumoto et al., 2004).

In the present study, dietary Bs was also associated with less skatole produced by the fermentation broths, compared with the control group. It was reported previously that bacteria could affect the pathway of skatole formation by way of tryptophan metabolism (Li, 2009; Vhile et al., 2012), although the microorganisms tested were not Bs. The identity of the microorganisms responsible for the conversion of tryptophan to skatole has not been established. However, bacteria known to facilitate the degradation of skatole are: lactic acid bacteria 11201 (Yokoyama et al., 1983), Clostridium drakei and C. scatologenes (Whitehead et al., 2008), C. disporicum (Li, 2009), and C. scatologenes ATCC 25775 (Doerner et al., 2009).

The predominant bacteria discovered in the manure broth in this study were Streptococcus alactolyticus AF201899 and Lactobacillus amylovorus. No reports regarding the function of Streptococcus alactolyticus AF201899 have been published previously. Rinkinen et al. (2004) demonstrated that $S$. alactolyticus was the predominant lactic acid bacteria in the empty intestine and feces. S. alactolyticus could secret $\beta$-glycoside hydrolase, $\alpha-$ galactosidase, amylase, urease, acidic galactose, and galactosidase.

It has also been reported that lactic acid in the daily diet could reduce skatole production in the gut (Nowak and Libudzisz, 2009). Investigated as a probiotic, L. amylovorus secreted lactic acid and amylase (Eom et al., 2009) and promoted the growth of lactobacilli and bifidobacteria when galactooligosaccharides and Bifidobacterium were added to an in vitro model of the large intestine (Martinez et al., 2013). L. amylovorus was not found to degrade skatole directly. Skatole could be degraded in vitro by Streptococcus 6020 (Li, 2011). The effect of S. alactolyticus AF201899, L. amylovorus, and Bacillus MA001 need further investigation.

In this study, the effect of Bs in reducing ammonia, $\mathrm{H}_{2} \mathrm{~S}$, and skatole occurred in the swine gut, in the in vitro manure fermentation process, or both. Suárez-Estrella et al. (2013) reported that Bs could reduce changes in bacterial species during vegetable anaerobic composting, but there are no reports on the amount of ammonia, $\mathrm{H}_{2} \mathrm{~S}$, or skatole. In the present study, some isolated bacteria could not be grown in culture, which is consistent with the general knowledge that there are many undiscovered bacteria in the swine intestine. Further investigations are needed to elucidate the effect of Bs on the production of ammonia, $\mathrm{H}_{2} \mathrm{~S}$, and skatole.

\section{Effect of added L-tryptophan, casein, and fructan on} ammonia, $\mathrm{H}_{2} \mathrm{~S}$ and skatole production

In the present study, tryptophan as an additive was the main variant that affected ammonia production in the $\mathrm{Bs}^{+}$ group, but not the $\mathrm{Bs}^{-}$group. No significant interaction was observed between tryptophan and Bs, indicating that added tryptophan might affect the nitrogen level in feces through other bacteria. Pierce et al. (1931) discovered that yeast might enhance nitrogen and indole production; added tryptophan, cysteine, and phenylalanine inhibited ammonia production in feces. There has been no report regarding whether added tryptophan could affect the production of $\mathrm{H}_{2} \mathrm{~S}$ in swine manure. In our study, added tryptophan was not the main element affecting the production of $\mathrm{H}_{2} \mathrm{~S}$.

We found that added tryptophan was the main variant affecting the amount of tryptophan and skatole produced in the fermented manure broth. This is consistent with the previous discovery that skatole in swine blood could be increased by injecting tryptophan into the swine appendix (Jensen, 2006). However, it was also found that addition of tryptophan into the daily diet had no significant effect on the level of skatole (Wesoly and Weiler, 2012). The differences might be caused by how the tryptophan was acquired by the swine or how it interacted with the manure. Wesoly and Weiler (2012) indicated that the insignificance of dietary tryptophan might be because tryptophan might be absorbed by the small intestine, instead of being utilized by bacteria in the colon. In the present study, added Ltryptophan showed no significant effect on skatole in either the $\mathrm{Bs}^{+}$or $\mathrm{Bs}^{-}$group (same k value, $r=0.9992$ ), indicating that the fermentation of $\mathrm{Bs}$ in the intestine might not be simulated by the fermentation of tryptophan in vitro.

In this study, casein was the main factor affecting ammonia production in the control group, but was not significant for $\mathrm{H}_{2} \mathrm{~S}$ production, which is consistent with the reports of Powers et al. (2007). They showed that a diet balanced in amino acids with low crude proteins helped to reduce the ammonia level in feces, but exhibited no effect on $\mathrm{H}_{2} \mathrm{~S}$. We found that the combination of dietary Bs with casein added to the fermentation broth was significantly associated with a reduction in ammonia $(\mathrm{p}=0.0395)$, but not $\mathrm{H}_{2} \mathrm{~S}(\mathrm{p}=0.9505)$ produced from the fermentation broth. This was in accord with the various effects of different concentrations of casein on ammonia production in both the $\mathrm{Bs}^{+}$and $\mathrm{Bs}^{-}$groups $(r=-0.1551)$. The effect of casein on ammonia production may be related to the protease secreted by Bs. Casein was not the main additive to affect skatole production. This is consistent with the conclusion of Lin et al. (1992) that daily diet had no effect on the production of skatole. Lundstrma et al. (1994) reported that an increase in the concentration of skatole did not correlate with an increase of protein. Casein or dietary proteins could result in changes in the microbiota in the intestine and therefore affect the fermentations (An et al., 2014).

Fructan, as a probiotic, modifies the microflora by increasing the amount of beneficial bacteria (Salazar et al., 
2014). In the present study, the addition of fructan to fermentation broths was associated with a reduction in $\mathrm{H}_{2} \mathrm{~S}$, which correlated with the addition of dietary Bs. This is similar to a previous study (Zhao et al., 2013), which reported that a $1 \%$ addition of fructan had no effect on fertility, but lactic acid bacteria dramatically increased, with a significant decrease in $E$. coli $(\mathrm{p}<0.001)$; the amount of ammonia, $\mathrm{H}_{2} \mathrm{~S}$, and organosulfur significantly decreased ( $\mathrm{p}<0.05)$. Fructan had similar effects on $\mathrm{H}_{2} \mathrm{~S}$ in both the $\mathrm{Bs}^{+}$ and $\mathrm{Bs}^{-}$groups of the present study $(r=0.9981)$, indicating that Bs did not affect the amount of $\mathrm{H}_{2} \mathrm{~S}$. However, fructan did not significantly affect skatole, which is consistent with the conclusion drawn by $\mathrm{Xu}$ et al. (2002). They observed that $0.5 \%$ to $1 \%$ fructan increased the amount of indole, but not skatole, perhaps because the $\mathrm{pH}$ change resulted in a difference in the microbiota. In our research, although the microbiota of the $\mathrm{Bs}^{+}$and $\mathrm{Bs}^{-}$groups differed, we regret that the $\mathrm{pH}$ was not measured.

In this study, Bs was added to the diet, and not directly to the fecal fermentation broths. In fact, Bs can also be added directly to the broths. The production of crude proteins in fecal broth depended on the amount of casein added. Further study is required to determine the optimal means of introducing Bs to fermentations broths, and its interactions with different protein, tryptophan, and fructan concentrations.

\section{CONCLUSION}

Adding L-tryptophan to fecal fermentation broths increased production of skatole. Adding fructan to the broths reduced the production of $\mathrm{H}_{2} \mathrm{~S}$. The effect of casein on ammonia depended on the addition of Bs in the daily diet. Daily dietary Bs reduced the production of ammonia, $\mathrm{H}_{2} \mathrm{~S}$, and skatole in fecal fermentation broths.

\section{ACKNOWLEDGMENTS}

The authors would like to acknowledge Medjaden Bioscience for their assistance in manuscript preparation. This project was supported by a grant from the National Natural Science Foundation of China (31172245).

\section{REFERENCES}

An, C., T. Kuda, T. Yazaki, H. Takahashi, and B. Kimura. 2014. Caecal fermentation, putrefaction and microbiotas in rats fed milk casein, soy protein or fish meal. Appl. Microbiol. Biotechnol. 98:2779-2787.

Doerner, K. C., K. L. Cook, and B. P. Mason. 2009. 3Methylindole production is regulated in Clostridium scatologenes ATCC 25775. Lett. Appl. Microbiol. 48:125-132.

Eom, H. J., J. S. Moon, E. Y. Seo, and N. S. Han. 2009. Heterologous expression and secretion of lactobacillus amylovorus alpha-amylase in leuconostoc citreum. Biotechnol. Lett. 31:1783-1788.

Jensen, B. 2006. Prevention of boar taint in pig production. Factors affecting the level of skatole. Acta Vet. Scand. 48(Suppl 1):S6.

Jeon, B. S., J. H. Kwag, Y. H. Yoo, J. O. Cha, and H. S. Park. 1996. Effects of feeding enzymes, probiotics or yucca powder on pig growth and odor-generating substances in feces. Korean $\mathrm{J}$. Anim. Sci. 38:52-58.

Kim, H. J., J. S. Woo, O. S. Kwon, B. J. Min, K. S. Shon, J. H. Jo, Y. J. Chen, and I. H. Kim. 2005. Effects of bacillus subtilis supplementation on egg quality, blood characteristics and fecal NH3-N in laying hens. Korean J. Poult. Sci. 32:9-14.

Lee, S. J., N. H. Shin, J. U. Ok, H. S. Jung, G. M. Chu, J. D. Kim, I. H. Kim, and S. S. Lee. 2009. Effects of dietary synbiotics from anaerobic microflora on growth performance, noxious gas emission and fecal pathogenic bacteria population in weaning pigs. Asian Australas. J. Anim. Sci. 22:1202-1208.

Li, C. 2009. Effects of Dietary Fiber on Skatole Levels in Swine Body and the Underlying Regulatory Mechanisms. Ph.D Thesis, Zhejiang University, Hangzhou, China. VIII.

Li, F. 2011. Degradation of Skatole That Caused Boar Taint by Lactic Acid Bacteria. Ph.D Thesis, Southwest University, Chongqing, China. 141-142.

Lin, R. S., M. W. Orcutt, R. D. Allrich, and M. D. Judge .1992. Effect of dietary crude protein content on skatole concentration in boar serum. Meat Sci. 31:473-479.

Lundströma, K., B. Malmforsb, S. Sternb, L. Rydhmerb, L. Eliasson-Sellingc, A. B. Mortensend, and H. P. Mortensend. 1994. Skatole levels in pigs selected for high lean tissue growth rate on different dietary protein levels. Livest. Prod. Sci. 38:125-132.

Martinez, R. C. R., H. R. Cardarelli, W. Borst, S. Albrecht, H. Schols, O. P. Gutiérrez, A. J. H. Maathuis, B. D. G. de Melo Franco, E. C. P. De Martinis, E. G. Zoetendal, K. Venema, S. M. I. Saad, and H. Smidt. 2013. Effect of galactooligosaccharides and bifidobacterium animalis Bb-12 on growth of lactobacillus amylovorus DSM 16698, microbial community structure, and metabolite production in an in vitro colonic model set up with human or pig microbiota. FEMS Microbiol. Ecol. 84:110-123.

Nowak, A. and Z. Libudzisz. 2009. Ability of probiotic lactobacillus casei DN 114001 to bind or/and metabolise heterocyclic aromatic amines in vitro. Eur. J. Nutr. 48:419-427.

Powers, W. J., S. B. Zamzow, and B. J. Kerr. 2007. Reduced crude protein effects on aerial emissions from swine. Appl. Eng. Agric. 23:539-546.

Rinkinen, M. L., J. M. K. Koort, A. C. Ouwehand, E. Westermarck, and K. J. Björkroth. 2004. Streptococcus alactolyticus is the dominating culturable lactic acid bacterium species in canine jejunum and feces of four fistulated dogs. FEMS Microbiol. Lett. 230:35-39.

Salazar, N., E. M. Dewulf, A. M. Neyrinck, L. B. Bindels, P. D. Cani, J. Mahillon, W. M. de Vos, J. P. Thissen, M. Gueimonde, C. G. de Los Reyes-Gavilán, and N. M. Delzenne. 2014. Inulin-type fructans modulate intestinal Bifidobacterium species populations and decrease fecal short-chain fatty acids in obese women. Clin. Nutr. http://dx.doi.org/10.1016/ j.clnu.2014.06.001 
Su, Y., W. Yao, and W.Y. Zhu. 2006. Changes of bacterial flora from hindguts of piglets after oral administration of lactobacillus amylovorus $\mathrm{S} 1$ as a probiotic strain. Wei Sheng Wu Xue Bao. 46:961-966.

Suárez-Estrella, F., M. M. Jurado, M. C. Vargas-García, M. J. López, and J. Moreno. 2013. Isolation of bio-protective microbial agents from eco-composts. Biol. Control 67:66-74.

Vhile, S. G., N. P. Kjos, H. Sørum, and M. Øverland. 2012. Feeding jerusalem artichoke reduced skatole level and changed intestinal microbiota in the gut of entire male pigs. Animal 6:807-814

Wesoly, R. and U. Weiler. 2012. Nutritional influences on skatole formation and skatole metabolism in the pig. Animals 2:221242.

Whitehead, T. R., N. P. Price, H. L. Drake, and M. A. Cotta. 2008. Catabolic pathway for the production of skatole and indoleacetic acid by the acetogen clostridium drakei, Clostridium scatologenes, and swine manure. Appl. Environ. Microbiol. 74:1950-1953.

Wutzke, K. D., M. Lotz, and C. Zipprich. 2010. The effect of preand probiotics on the colonic ammonia metabolism in humans as measured by lactose- $\left[{ }^{15} \mathrm{~N}_{2}\right]$ ureide. Eur. J. Clin. Nutr. 64:1215-1221.

Xu, Z. R., C. H. Hu, and M. Q. Wang. 2002. Effects of fructooligosaccharide on conversion of L-tryptophan to skatole and indole by mixed populations of pig fecal bacteria. J. Gen. Appl. Microbiol. 48:83-89.
Yokoyama, M. T., and J. R. Carlson. 1974. Dissimilation of tryptophan and related indolic compounds by ruminal microorganisms in vitro. Appl. Environ. Microbiol. 27:540-548.

Yokoyama, M. T., K. A. Johnson, and J. R. Carlson. 1983. Factors influencing the production of $\mathrm{p}$-cresol and skatole by lactobacillus isolated from the rumen and pig feces. Proceedings of XVII Conference on Rumen Function, Chicag, IL, USA. 17:19-20.

Yumoto, I., K. Hirota, S. Yamaga, Y. Nodasaka, T. Kawasaki, H. Matsuyama, and K. Nakajima. 2004. Bacillus asahii sp. nov., a novel bacterium isolated from soil with the ability to deodorize the bad smell generated from short-chain fatty acids. Int. J. Syst. Evol. Microbiol. 54:1997-2001.

Zhang, Q., M. Hu, R. Zhu, X. Ren, Y. Wu, H. Wang, Y. Liu, and S. Wang. 2009. Microbial properties and application of superior bacteria in deep-litter ecosystem for piggery. Shandong Agricultural Sciences (China). 4:99-105.

Zhang, Z., Y. Wu, W. Cheng, and R. Wu. 2000. Single strand conformation polymorphism analysis of K-ras gene mutations by capillary electrophoresis with laser-induced fluorescence (LIF) detector. Clin. Chim. Acta. 301:205-211.

Zhao, P. Y., J. P. Wang, and I. H. Kim. 2013. Evaluation of dietary fructan supplementation on growth performance, nutrient digestibility, meat quality, fecal microbial flora, and fecal noxious gas emission in finishing pigs. J. Anim. Sci. 91:52805286. 